\title{
The Role of Video Support in Physical Class Management: A Review of Literature
}

\author{
Pierre Al-Khoury ${ }^{1}$, Dory Daw ${ }^{2}$, Elie El-Khoury ${ }^{3}$ \\ ${ }^{I}$ Vice President for Development, Lebanese German University, Lebanon, \\ ${ }^{2} \mathrm{MBA}$ Lecturer at University of Leicester, UK. \\ ${ }^{3}$ Associate Dean, Faculty of Business Administration, Lebanese Canadian University, Lebanon \\ *Corresponding Author: Pierre Al-Khoury, Vice President for Development, Lebanese German \\ University, Lebanon. Email: Lebanonp.khoury@lgu.edu.lb

\begin{abstract}
Student motivation is the essence of the learning process. One way of increasing this motivation is the use of videos in class as an additional tool in order to enhance the quality of education and make it more efficient. This paper aims to review the literature related to the consequences of referring to videos to educate students in physical classes in all disciplines and to show its importance in increasing their motivation for the matter under study. In addition, it locates the domains where this educational tool has been applied and point out the abilities developed by the students that were subjected to such videos.
\end{abstract}

\section{INTRODUCTION}

Lately, technology hits in all domains. And whenever it hits, it enhances and gives advantages. Technology became a need that facilitates, accelerate, and support human's life and way of living. One of the domains that got rich with what technology offered is the educational domain. Technology offers wide new techniques that can help better in classroom management issue. Every technique is unique and has its own characteristics. One of those rapidly growing techniques is using video session in class management. So, what are the role and the importance of video sessions in class management? And is it effective? This paper is aimed at exploring the effect of the use of videos for assessing the enhancement of students' learning motivation. The remainder of this paper is structured as follows; next section presents a literature review on motivation; third section explains the methodology we drew upon, and finally, fourth section describes the findings of the exploratory qualitative research centered on the effect of the use of videos upon students' motivation.

\section{LITERATURE REVIEW}

\subsection{Materials Used in Online Learning}

Students should have the abilities to communicate and use communication tools effectively as the elearning environment requires the student to be in a process of constant communication and interaction with content, instructor and other students. If the course is carried out by taking advantage of instructional materials during teaching-learning process, the material will address students' senses of sight and sound. Also, when the students are able to express their opinions with the help of the instructor, the number of sense organs participating will increase and what is attempted to be learnt will be more easily recalled.

There is a bidirectional information flow and interaction between student, instructor and content in teaching environments. According to Chou, Peng and Chang (2010), interaction represents the functions or actions that can be utilized by users and enable them to study the content presented via computer and get feedback; furthermore it is an important element for the quality and success of online learning. Within online learning, the instructor and students are far from each other geographically. Therefore, it is important to use the communication tools effectively. An efficient learning environment should offer synchronous education (virtual classroom), video, animation, simulation software, discussion and chat environments, games, and self-evaluation environments in addition to text, sound and graphics. 
Chou et al. (2010) suggest that there are five types of student-centered interaction:

- Student-interface interaction: Students' effective and easy access to and ability to control the interface.

- Student-self interaction: Students' ability to pursue his/her improvement in learning.

- Student-content interaction: Providing interaction with all the materials available in the learning environment.

- Student-instructor interaction: Ensuring interaction between instructor and student by means of communication channels provided by the system.

- Student-student interaction: Ensuring interaction with other students using the system via communication tools.

E learning can be organized as synchronous or asynchronous. During synchronous e learning, the instructor and students interact with each other using communication technologies such as a live course, chat rooms, or video conference at different places but the same time. However, during asynchronous e learning, the instructor and students interact with each other via technologies such as a forum or e-mail at different places and times.

In addition, learner-focused recordings delineating classrooms and occasions arranged inside genuine relevant settings, advance top to bottom investigation and higher request considering (Risko, Yount, and McAllister, 1992). Recordings can likewise give a typical perspective for reflection and the social development of information about educating (Barab, Hay, and Duffy, 1999) through deliberate altering and creation that attracts unequivocal thoughtfulness regarding a pre-recognized arrangement of abilities, practices, or learning (Fishman, 2003). Nonetheless, originators of viable video must see how to mastermind support with the goal that consideration is attracted to important data and learners are upheld in their development of new information as opposed to being diverted or overpowered by boosts (Salomon, 1994)

Also, an examine on expert improvement has uncovered that educators advantage from learning in situations that are learner focused (Bransford, Brown, and Cocking, 2000) and deliberately intended to expand upon the learner's qualities, information, and premiums. One approach to accomplish this objective is by giving learning openings that are particularly custom fitted to the learners' needs and housed inside a pertinent relevant setting (Loucks-Horsley and Matsumoto, 1999). Also, significant learning happens when learners have the chance to build importance from various representations of a similar material (Mayer, Moreno, Boire, and Vagge, 1999) as opposed to depending on a solitary perspective or point of view. Video is one approach to give a learning situation that both are learner and information focused and that contains a large number of points of view (Lampert and Ball, 1998).

There is a highly dependence on technological services. One of those services was the effective usage of video sessions in classroom management. Such method adds an advantage on teaching and on how to mix between lecture and video. This combination between old style (lecture) and the new one (using video) attracts student's attention and more interested.

Within the context of the knowledge economy, Marx and Frost, suggest that video can be a powerful motivator and context setter for student learning.By using different tools to present contents, lecturers succeeded in enhancing students' intrinsic motivation and encouraged them to improve their learning outcomes. A lecturer of the degree in Business Administration said that after posting the first videos he was pleased to receive congratulations emails from students. The biggest advantage was that students could play the videos as often as they deemed necessary to understand the resolution of the problem. Some lecturers observed that in the session in which they used videos students had fewer doubts.

Continuous data analysis and iteration identified a pattern in the lecturers' narratives. This pattern was used to classify the types of motivation generated by the use of low-cost videos as a complementing teaching material. The first type of motivation is generated by the "novelty" brought about by the use of the videos. The second type is derived from the "recognition" of the lecturers' effort that encouraged students to respond them in the same way. Finally, the third type is "understandability". During the course many students are unable to comply with the requirements of continuous 
assessment. In order to guide these students, some lecturers created videos that incorporated a synthesis of all the issues generated during the course.

Although the main pedagogical objectives initially set by professors only comprised efficiency and comprehension, the majority of lecturers have also made reference to the impact of videos upon the enhancement of students' motivation.

Recordings are a powerful approach to "submerge pre service instructors in issues, and arrangements of showing practice" (Richardson and Kile, 1999, p. 122) by giving a true setting inside which instructors can arrange their learning (Brown, Collins, and Duguid, 1989). Utilizing video to arrange learning inside complex classroom settings energizes profound investigation and higher request thinking with respect to preservice instructors (Risko et al., 1992) while giving a shared belief to educators to investigate and talk about issues of practice. Recordings can appear, for instance, educators managing understudy confusions, conduct administration, and the instructing of complex material, allowing viewers to consider and examine circumstances that they may experience in their own particular educating. The video medium empowers customization of the learning background by giving pictures of classroom practice that is most important to a given educator's needs (Bransford et al., 2000).

In fact, video instructional exercises offer a multidimensional affair that may consolidate outlines, slides, photographs, illustrations, portrayal, screenshots, on-screen inscriptions, music and live video. This permits understudies with various learning capacities to hold data in a technique more suited to them. The more that apparatuses are used in a video instructional exercise, the more ways an understudy needs to concentrate on, and hold the data. A number of these interactive media helps may be excessively intricate, making it impossible to routinely use in a physical classroom environment.

In addition, video sessions takes into consideration collaboration, for example, PC programming lessons, give a "hands-on" approach that can strengthen the data. Rather than simply hearing or seeing the data, the understudy can react to prompts utilizing a console and mouse to answer inquiries or get to additional learning components. Recordings may likewise be joined by archives that can be downloaded with layouts of the video lesson or notes with spaces for understudies to sort in as they watch the video instructional exercise. By utilizing these intelligent components, understudies may profit by being acquainted with new advancements. Another sort of intelligence includes two-way correspondence that can occur amongst understudies and a video instructor if the video is transmitted live on the web, despite the fact that they are in various physical areas - through webcams, mouthpieces and talk programming.

At last, a video can display just a preview of what is going on in a specific class amid a specific time of a specific day. It doesn't catch the setting of the lesson or the history and culture of the class all in all. This relevant data is fundamental when attempting to decipher classroom occasions and showing hone, specifically (Lampert and Ball, 1998). Indeed, even with these inadequacies, video is an effective device that can be utilized to bolster and support instructor learning. Video gives numerous chances to investigate and examine the complexities of classroom practice. So as to completely tackle the force of video as an instructive medium, it is vital to utilize the different plan methodologies illustrated in this article so instructors are bolstered in their learning. Giving distinctive platforms to attract thoughtfulness regarding striking substance and help instructors concentrate on particular events of practice serves to improve the instructional estimation of video materials.

\subsection{Student-Instructor Interaction}

The instructor's facilitative presence, prompting the students by means of using tools like forum, chat, live courses, e-mail and giving feedback in e-learning environments are among the most important factors of these environments. The instructor should be able to use course tools, ensure the students' engagement in the process via inquiry and discussion, try to increase the motivation by different learning techniques, ensure collaboration between students, prepare guides for them, manage time properly, plan and monitor the learning stages.

In a literature study that was carried out by Chou et al. (2010), the tools used for ensuring studentinstructor interaction were: class roster e-mail, bulletin board systems, synchronous communication, social tools, grouping the students, ensuring students ${ }^{6}$ assignment submission and giving the related feedback, online examination, voting and questionnaire, and comments about the course and 
instructor. Effective usage of these tools will motivate the student and consequently will contribute to positive student satisfaction.

The multiplication of natural video altering apparatuses and free media sharing destinations has made it conceivable to effectively create and circulate instructive recordings to a wide group of onlookers of instructors. Most new PCs are outfitted with programming, for example, Windows Movie Maker (PC) or iMovie (Mac), both of which furnish instructor teachers with a broad scope of elements with which to make proficient looking video.

\subsection{Instructional Environment Design}

The main objective of web based instructional environment design is to draw the student's attention and ensure his or her motivation. That's why the design should include high level cognitive activities, support usage of a wide range of tools and sources, discuss the course and social and life skills together, use technology as a tool, encourage the student to interact with the software, help the student complete learning purposes without getting tired or bored or experiencing any conflict.

The primary goal of an instructional interface design that enables the communication between user and computer is to ensure easy surfing by means of assistant tools during learning and prompt the student directly to related information by using recognizable clues like subsidiary signs or tools.

\subsection{Attitude Towards E-Course}

The factor that has the greatest effect on the success of e-learning is the student as well as the instructor's preparation for the course. One of the determinants that affect the student's success and satisfaction with the system, and helps him/her learn permanently, is the student's attitude towards learning. There is a close relationship between attitude and an individual's personality characteristics, the social and cultural environment in which he/she lives, knowledge and experiences. Attitude is composed of sensual, cognitive and behavioral components. It determines what an individual knows about an issue (mental factor), how he/she will approach it and what kind of manner he/she will take up against it (behavioral factor).

Positive student attitudes towards e-learning and computers will improve their learning levels. Liaw, Huang and Chen (2007) state that students of the instructors who display a positive attitude in elearning seem to be more willing to use the system and the students who display a positive attitude use the system more effectively. Comprehending the attitude of the instructor and learners towards technology is essential to making learning more efficient and attractive (Liaw et al., 2007). Furthermore, identification of the learner's motivation, confidence, trust, anxiety about computers, fear, anxiety, pleasure, excitement, pride and embarrassment is required for the success of the system (Ozkan\&Koseler, 2009). As the students that engage in the system voluntarily for a specific purpose are more motivated than the others, they are likely to be more successful (Gulbahar, 2009, p:65).

\subsection{Course Content and Teaching Process}

In addition to the representation quality of the information, quality of interaction, and perceived benefit and ease of usage, quality of the content has a significant impact on student satisfaction; as the content quality improves, potential users will find the system more useful and adopt it. E-learning processes that do not adhere to pedagogical principles, lecturers resistant to change, learners who do not know about e-learning, poor student performance and low-quality content hamper the learning process.

In the teaching process of the course, the instructor must develop constructive techniques to support the students' engagement in the course and make use of teaching strategies in order to ensure the students participate in discussions cognitively. In order for that, the instructor can explain what he/she expects from the students, how they must discuss and how they will be evaluated via a discussion guide during and after discussion (Gulbahar; 2009, p:157). In the teaching process, the quality of the course and student motivation will improve provided that students have frequent and high-quality interaction with the instructor and other students, they are supported when necessary, few technical problems occur and they use many interactive materials. 


\subsection{Readiness for Online Learning}

Online learning environments provide students with flexibility in planning and controlling their learning. The student forms his/her own learning plan by accessing the content he/she chooses in his/her free time, doing exercises and using the material which he/she wants. Learning will be facilitated if the student has enough technical skill, ability to self-learn and communicate, and motivation (i.e. a high level of readiness).

The learner who has a high level of readiness can comment on the topic and do assignments more easily by comprehending the subjects sooner; on learning the previous topic thoroughly, he/she could be ready to move on to the next one (Harman \&Celikler, 2012).

Aruk (2008) suggests that readiness has three basic aspects: social, cognitive and educational. Social readiness means ensuring interaction by dual communication in virtual education environments, turning into an information society and undertaking a common responsibility for the outcome and results arising during the education process of interacting learners. Cognitive readiness requires the learner to have the skill of critical thinking. Educational readiness necessitates accessing information through multiple resources, evaluating, sharing and discussing it independently of time and place and using it in life when required (Aruk, 2008).

In web based learning environments, learners' performance is closely related to their computer and internet skills, comprehension of the internet, attitudes and behavior in online environment (Hung et. al, 2010). In addition to external factors like past experiences and educational level, motivation, capacity for self-directed learning and ability to work with the materials offered as text are essential for the learner to be successful in an e-learning environment (Warner, Christie and Choy, 1998).

Online learning readiness focuses on the ability to manage time and adapt to the self-directed nature of online learning which is self-learning, understanding personal learning styles and experiences (Lau, 2008). Self-directed learners have the skills to access and process the information for a specific purpose.

Determining the readiness level of the learners who do not have experience for this method of learning contributes to both the learner and to the instructor's course plan. In order for e-courses to be conducted without any problems, it is essential to assess the effect of students' readiness level on satisfaction.

When the studies regarding readiness in Turkey examined, it is seen that factors such as technical skills, elements affecting success, access to technology, motivation, attitude and personal characteristics, self-directed learning, online skills, online communication, learner control and time management have generally been investigated but only in one study has readiness been associated with satisfaction.

\section{CONCLUSION}

This research demonstrated that the use of videos has a positive effect upon students' perception regarding the enhancement of their learning motivation.

As discussed throughout this paper, the lecturers followed up the process of videos implementation and received positive feedback from students throughout the process. As exposed by lecturers in different interviews, these videos allow providing more rapid explanations as compared to verbal or written forms.

The lecturers noticed an increased level of students' motivation and interest in the subject. This gave them a sense of satisfaction for a well done job and encouraged them to continue working on educational innovation.

For all of these reasons, the authors recommend the use of educational videos as a common practice in different universities.

Therefore, audiovisual contents promote dynamism in classes, helping subjects' comprehension, making contents more attractive and reducing absenteeism in classrooms but they should be associated with written explanations. 


\section{REFERENCES}

[1] Chou, C., Peng, H. Y. \& Chang, C. Y. (2010). The Technical Framework of Interactive Functions for Course-Management Systems: Students' Perceptions, Uses and Evaluations. Computers \& Education, 55(3), 1004-1017.

[2] Gulbahar, Y. (2009). E-Leraning. Ankara: PegemAkademi

[3] Harman, G. \&Çelikler, D. (2012). A Review Study About Important Of Readiness in Education. Journal of Research in Education and Teaching, 1(3), 140-149. Retrieved from http://www.jret.org/File Upload/ks281142/File/16z.harman.pdf

[4] Lau, C.Y., (2008). Effects of Personal Characteristics on Learner Online Learning Readiness. International Conference. Sustainability in Higher Education: Directions for Change, Edith Cowan University, Perth Western Australia. Retrieved from: http://ro.ecu.edu.au/ceducom/31/

[5] Liaw, S.S., Huang, H.M. \& Chen, G.D. (2007). Surveying Instructor and Learner Attitudes Toward Elearning, Computers \& Education, 49(4), P. 1066-1080, ISSN 0360-1315. Retrieved from: http://dx.doi.org/10.1016/j.compedu.2006.01.001

[6] Ozkan, S. \& Koseler, R. (2009). Multi-Dimensional Students ' Evaluation of E-Learning Systems in the Higher Education Context: An Empirical Investigation. Computers \& Education, 53(4), 1285-1296. Retrieved from http://dx.doi.org/10.1016/j.compedu.2009.06.011

[7] Fisch, S.M. (2003). The impact of Cyberchase on children's mathematical problem solving: Cyberchase Season 2 executive summary. Teaneck, NJ: Media Kidz Research \& Consulting.

[8] Barab, S., A., Hay K. \& Duffy, T. (1999) Grounded construction and how technology can help. Technology Trends, 43(2), 15-23

[9] Salomon, G. (1979). Interaction of media, cognition and learning. San Francisco, CA: Jossey-Bass. (Published again by Lawrence Erlbaum, 1994)

[10] Bransford, John D., Ann L. Brown and Rodney R. Cocking (eds). 2000. How People Learn: Brain, Mind, Experience and School. Washington D.C.: National Academy Press. pp. 3-23

[11] Lampert, M., \& Ball, D. L. (1998). Teaching, multimedia, and mathematics: Investigations of real practice. New York: Teachers College Press

[12] S.-S. Liaw et al. / Computers \& Education 49 (2007) 1066-1080 1067

[13] Huang T, et al. (2010) Using Gene Reg to construct time delay gene regulatory networks. BMC Res Notes $3(1): 142$

[14] Brown, J. S., Collins, A., \& Duguid, P. (1989). Situated cognition and the culture of learning. Educational researcher, 18(1), 32-42

Citation: Pierre Al-Khoury, Dory Daw, Elie El-Khoury. "The Role of Video Support in Physical Class Management: A Review of Literature" International Journal of Managerial Studies and Research (IJMSR), vol 5, no. 12, 2017, pp. 20-25. doi:http://dx.doi.org/10.20431/2349-0349.0512003.

Copyright: (C) 2017 Authors. This is an open-access article distributed under the terms of the Creative Commons Attribution License, which permits unrestricted use, distribution, and reproduction in any medium, provided the original author and source are credited. 